\title{
Introduction of Ultra-High-Field MR Imaging in Infants: Preparations and Feasibility
}

(D) K.V. Annink, (D) N.E. van der Aa, (D). Dudink, (D). Alderliesten, (D)F. Groenendaal, (D) M. Lequin, (D)F.E. Jansen, (D) K.S. Rhebergen, (D) P. Luijten, (D). Hendrikse, (D) H.J.M. Hoogduin, (DE.R. Huijing, (DE. Versteeg, (D)F. Visser, (D) A.J.E. Raaijmakers, (DE.C. Wiegers, (DD.W.J. Klomp, DJ.P. Wijnen, and (D) M.J.N.L. Benders

\begin{abstract}
BACKGROUND AND PURPOSE: Cerebral MR imaging in infants is usually performed with a field strength of up to $3 T$. In adults, a growing number of studies have shown added diagnostic value of 7T MR imaging. 7T MR imaging might be of additional value in infants with unexplained seizures, for example. The aim of this study was to investigate the feasibility of 7T MR imaging in infants. We provide information about the safety preparations and show the first MR images of infants at 7T.

MATERIALS AND METHODS: Specific absorption rate levels during 7T were simulated in Sim4life using infant and adult models. A newly developed acoustic hood was used to guarantee hearing protection. Acoustic noise damping of this hood was measured and compared with the $3 \mathrm{~T}$ Nordell hood and no hood. In this prospective pilot study, clinically stable infants, between termequivalent age and the corrected age of 3 months, underwent 7T MR imaging immediately after their standard 3T MR imaging. The 7T scan protocols were developed and optimized while scanning this cohort.

RESULTS: Global and peak specific absorption rate levels in the infant model in the centered position and 50-mm feet direction did not exceed the levels in the adult model. Hearing protection was guaranteed with the new hood. Twelve infants were scanned. No MR imaging-related adverse events occurred. It was feasible to obtain good-quality imaging at 7T for MRA, MRV, SWI, singleshot T2WI, and MR spectroscopy. TIWI had lower quality at 7T.
\end{abstract}

CONCLUSIONS: 7T MR imaging is feasible in infants, and good-quality scans could be obtained.

ABBREVIATIONS: $\mathrm{dB}(\mathrm{A})=\mathrm{A}$-weighted decibels; $-50-\mathrm{mm} \mathrm{FH}=50 \mathrm{~mm}$ from the isocenter in feet direction; $+50-\mathrm{mm} \mathrm{FH}=50 \mathrm{~mm}$ from the isocenter in head direction; SAR = specific absorption rate

nfants who are admitted to the neonatal intensive care unit are at risk of delayed or impaired neurodevelopmental outcome due to brain injury, cerebral malformations, and genetic or metabolic disorders. ${ }^{1,2}$

MR imaging is the criterion standard to assess brain development, malformations, and injury in infants. ${ }^{3}$ The first neonatal 3T field strength MR imaging scans were reported in $2004,{ }^{4}$ and $3 \mathrm{~T}$ scanners are now routinely used by many centers. 3T MR imaging has several advantages compared with 1.5T MR imaging. The quality of the MR images improved because of the increased SNR, leading to higher spatial resolution, improved susceptibility contrast, and increased chemical shift dispersion leading to

Received December 16, 2019; accepted after revision May 19, 2020.

From the Departments of Neonatology (K.V.A., N.E.v.d.A., J.D., T.A., F.G., M.J.N.L.B.), and Paediatric Neurology (F.E.J.), University Medical Center Utrecht Brain Center, and the Departments of Radiology (M.L., P.L., J.H., H.J.M.H., E.R.H., E.V., F.V., A.J.E.R., E.C.W., D.W.J.K., J.P.W.), and Otorhinolaryngology and Head and Neck Surgery (K.S.R.), University Medical Center Utrecht, University Utrecht, Utrecht, the Netherlands.

K.V. Annink and N.E. van der Aa shared first authorship.

J.P. Wijnen and M.J.N.L. Benders shared last authorship. improved quality of MR spectroscopy. ${ }^{5,6}$ The increased SNR in neonatal 3T MR imaging also led to shorter acquisition times. ${ }^{6}$

In adults, the introduction of ultra-high-field MR imaging provided new opportunities, further improving the spatial resolution at $7 \mathrm{~T}$ compared with $3 \mathrm{~T}$ when the same acquisition times were used. ${ }^{7}$ This feature provided additional anatomic information. ${ }^{8}$ At $7 \mathrm{~T}$, the sensitivity to susceptibility is strongly increased, enabling

The study was funded by the Dr. C.J. Vaillant Foundation. The PhD position of the first author Kim Annink is supported by the Horizon 2020 Research and Innovation Programme of the European Union (grant agreement No 667224, ALBINO).

Paper previously presented as a poster at: Congress of the Joint European Neonatal Societies/Eastern Society for Pediatric Research Conference, September 17-21, 2019; Maastricht, the Netherlands; and in part, at: International Society for Magnetic Resonance in Medicine Workshop on Ultrahigh Field Magnetic Resonance, March 31 to April 3, 2019, Dubrovic, Croatia.

Please address correspondence to Manon J.N.L. Benders, MD, Department of Neonatology, UMC Utrecht Brain Center, University Utrecht, Lundlaan 6, 3508AB Utrecht, the Netherlands; e-mail: m.benders@umcutrecht.nl

-- Indicates open access to non-subscribers at www.ajnr.org

$\equiv$ Indicates article with supplemental on-line table.

http://dx.doi.org/10.3174/ajnr.A6702 


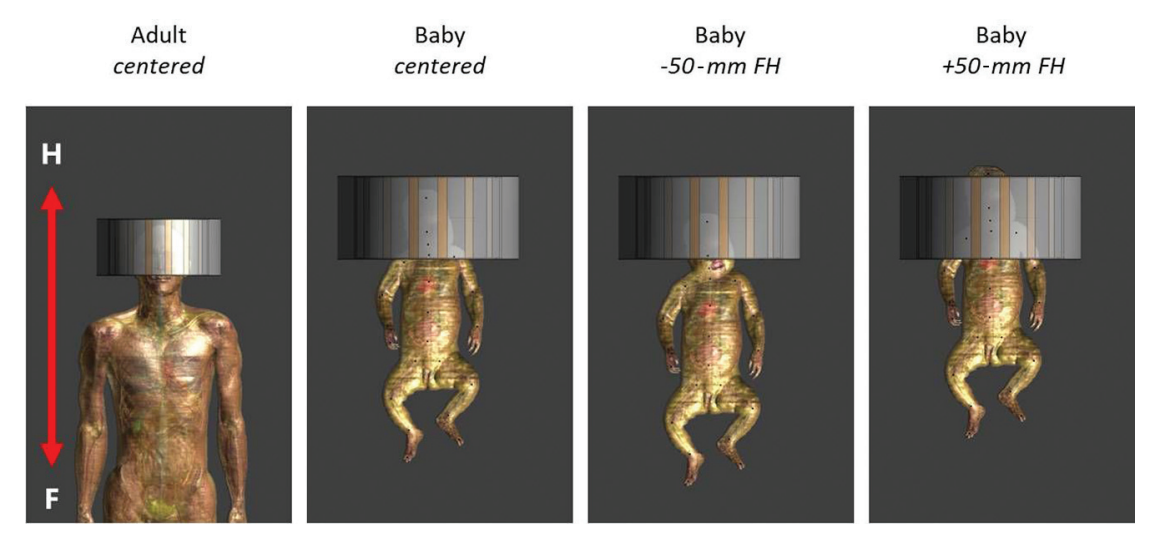

FIG 1. Different positions of the infant model in the radiofrequency coil. On the left, the adult head and torso are shown. They are used as a reference.

the diagnosis of microbleeds and visualization of microvasculature. Due to the increased chemical shift dispersion at 7T, additional metabolite peaks could be detected with MR spectroscopy., ${ }^{5,-11}$ Currently, accessibility of 7T MR imaging scanners in adult research is increasing rapidly, and 7T MR imaging is more often used for clinical purposes. The initial safety concerns of using 7T MR imaging in adults have been addressed in the past decades. The largest safety concern was an increase in body temperature because of the higher local and global specific absorption rate (SAR) for the same $\mathrm{B}_{1}{ }^{+}$at 7T. However, an increase in body temperature has not been reported in ultra-high-field MR imaging in adults or children., ${ }^{5,12}$ Besides the increased SAR, a higher static magnetic field increases the risk of attracting ferromagnetic objects, which can be prevented with screening for ferrometal before MR imaging. ${ }^{13}$ It also can potentially influence biologic systems, such as cardiac and neurophysiological responses, but harmful effects have never been described in follow-up studies in infants. ${ }^{13}$ Sensory symptoms such as vertigo, headaches, and an iron taste due to the varying gradient field ${ }^{5}$ were reported by patients undergoing 7T MR imaging; however, only 5\% rated these symptoms as very unpleasant. ${ }^{14}$ Acoustic noise protection should be guaranteed during the MR imaging, similar to 3T MR imaging.

While studies at $7 \mathrm{~T}$ have now been shown to be safe in adults, ${ }^{14,15}$ the literature about safety in children is scarce. In a study by Harris et al, ${ }^{16} 42$ children between 5 and 10 years of age underwent 7T MR imaging, which was well-tolerated and safe in all children. The Food and Drug Administration approved 7T MR imaging in infants of 1 month and older. ${ }^{17}$ The limit of the main static field in neonates is $4 \mathrm{~T}$ MR imaging. SAR limits are the same for adults and neonates. ${ }^{17}$

We initiated a feasibility pilot study in infants. This study shows the first MR images of infants at 7T and provides information about the safety preparations.

\section{MATERIALS AND METHODS}

\section{Preparation: SAR Simulation}

Using a radiofrequency simulation, we investigated whether MR imaging protocols could be translated from the adult to the infant brain without exceeding the SAR limits. Finite-difference time-domain simulations were performed using Sim4Life (Zurich Med Tech) to evaluate transmit efficiency and radiofrequency safety limits of the setup, assuming full decoupling of the receiver coils. The geometry and electrical circuits of the NOVA head coil (Nova Medical) for 7T were implemented in Sim4Life. The simulations were performed on a virtual infant model (Charlie, 2 months of age, 4.3 $\mathrm{kg}$ ) of the Integrated Taxonomic Information System virtual family ${ }^{18}$ in different positions in the coil (Fig 1), using the head coil in quadrature mode. The same simulations were performed on adult heads (male Duke, female Ella) of the virtual family ${ }^{18}$ as a reference. Local SAR levels (10-g average) for 1-W input power and global SAR levels (average SAR over the whole head) were calculated. Also, the average SAR per $\mathrm{B}_{1}{ }^{2}$ was calculated as the average SAR over the whole head divided by the average $\mathrm{B}_{1}{ }^{2}$ in a central section in the brain. The peak local SAR was defined as the highest SAR in the whole infant.

SAR simulations were validated by comparing simulations and measurements of $B_{1}$ maps of a spherical phantom and power measurements for data scaling (data not shown).

\section{Preparation: Acoustic Noise Protection}

At 3T MR imaging, acoustic noise protection is guaranteed by Alpine Muffy Baby (Alpine Hearing Protection), Natus MiniMuffs (Natus Medical), and a hood for acoustic noise protection, ${ }^{19}$ respectively, leading to $6.4-$ to $31.6-\mathrm{dB}, 7-\mathrm{dB}$, and 4 - to $13.6-\mathrm{dB}$ reduction. A prototype of the hood $(190 \mathrm{~cm}$ long) for noise protection that fits in the 7T MR scanner was developed using a layer of 5-cm foam (EASYfoam TC2; EASY Noise Control).

A test setup with a dummy MR imaging bore (old 7T MR imaging bore) was made in a sound-isolated booth to test the attenuation of acoustic noise with different hoods and no hood. We conducted all sound-level measurements using a sound-level meter (B\&K type 2250; Brüel \& Kjær). A microphone (B\&K, type 4189) was placed in the isocenter of the dummy bore to record the sound volumes in A-weighted decibels $9 \mathrm{~dB}(\mathrm{~A})$. Four speakers (Yamaha MSP5A; Hamamatsu) were positioned around this test setup: one on each end of the dummy bore and one on each side (Fig 2). The speakers were separately calibrated on an acoustic noise level of $55 \mathrm{~dB}(\mathrm{~A})$. The acoustic noise was measured with the $3 \mathrm{~T}$ hood, the 7T hood, and without a hood, with the acoustic noise coming from the speakers at both ends, both sides, and from all 4 speakers.

We measured the attenuation of the Alpine Muffy Baby and Natus MiniMuffs using the B\&K type 2250 G4 SLM and B\&K Artificial Ear type 4153. A stimulus (AudioNigma; Decos) of $80 \mathrm{~dB}(\mathrm{~A})$ was sent to an artificial ear.

\section{Study Population}

Clinically stable infants, between term-equivalent age and the corrected age of 3 months were included in this pilot study. 


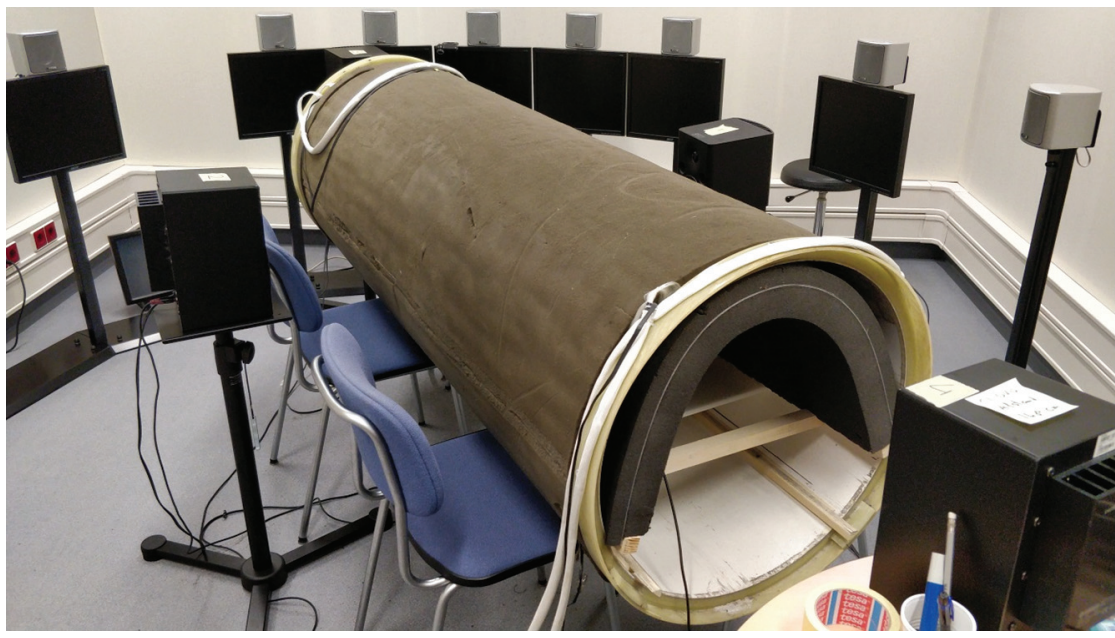

FIG 2. Setup for measuring acoustic noise at the MR imaging table in the presence of the hood. This test setup consisted of a dummy bore with dimensions similar to those of the 7T MR system with a 10-mm plastic plate of polyoxymethylene to create an MR imaging table. The speakers producing the sound are positioned at $28-\mathrm{cm}$ distance around the dummy bore to mimic the sound produced by the MR imaging scanner.

Table 1: Global and peak SAR levels

\begin{tabular}{|c|c|c|c|c|c|}
\hline & $\begin{array}{c}\text { Duke } \\
\text { Centered }\end{array}$ & $\begin{array}{c}\text { Ella } \\
\text { Centered }\end{array}$ & $\begin{array}{l}\text { Charlie } \\
\text { Centered }\end{array}$ & $\begin{array}{c}\text { Charlie } \\
-50- \\
\mathrm{mm} \text { FH }\end{array}$ & $\begin{array}{c}\text { Charlie } \\
+50- \\
\mathrm{mm} \mathrm{FH}\end{array}$ \\
\hline \multicolumn{6}{|l|}{ Global SAR levels } \\
\hline $\begin{array}{l}\text { Average SAR for } 1 \text { Watt input } \\
\text { power }\left(\mathrm{W} \mathrm{kg}^{-1}\right)\end{array}$ & 0.066 & 0.069 & 0.062 & 0.050 & 0.075 \\
\hline Average SAR per $\mathrm{B}_{1}^{2}\left(\mathrm{~W} \mathrm{~kg}^{-1} \mu \mathrm{T}^{-2}\right)$ & 0.462 & 0.465 & 0.289 & 0.454 & 0.474 \\
\hline $\begin{array}{l}\text { Average } B_{1}^{+} \text {in central section } \\
\text { for } 1 \text { Watt input power }(\mu T)^{a}\end{array}$ & 0.379 & 0.385 & 0.466 & 0.333 & 0.398 \\
\hline \multicolumn{6}{|l|}{ Peak local SAR levels } \\
\hline $\begin{array}{l}\text { Peak local SAR (10-g averaged) } \\
\text { for } 1 \text { Watt input power }\left(\mathrm{W} \mathrm{kg}^{-1}\right)\end{array}$ & 0.435 & 0.398 & 0.321 & 0.213 & 0.487 \\
\hline $\begin{array}{l}\text { Peak local SAR (10-g averaged) } \\
\text { per } B_{1}^{2}\left(\mathrm{~W} \mathrm{~kg}^{-1} \mu \mathrm{T}^{-2}\right)\end{array}$ & 3.04 & 2.63 & 1.48 & 1.92 & 3.08 \\
\hline
\end{tabular}

${ }^{a}$ The power optimization procedure of the MR imaging scanner software calibrates the needed input power to achieve a certain $B_{1}$ in the subject. This calibration is based on the average $B_{1}{ }^{+}$in a central section of the subject (brain in this case).

Infants with respiratory support or an intravenous catheter were excluded. They underwent 7T MR imaging immediately after their routine 3T MR imaging scan (both Philips Healthcare Best, The Netherlands). All infants were sedated with chloral hydrate before the 3T MR imaging in combination with the feed-bundle technique, as parts of routine clinical care. An additional dose of chloral hydrate before the 7T MR imaging was not allowed by the medical ethics committee. For neonatal scans of the brain at 7T, the 2-channel transmit 32-channel receive head coil (Nova Medical, Wilmington, MA) was used. The selection of sequences was based on the clinical indication. Details of the scan protocols can be found in the On-line Table. Hearing was protected as described above. Safety parameters were monitored before, during, between, and after the MR images. We monitored heart rate, peripheral oxygen saturation, temperature (core temperature before and after and abdominal skin temperature during the scans), and comfort scales. $^{20}$

This study was approved by the medical ethics committee of the University Medical Center Utrecht (NL66198.041.18), and written informed consent was obtained from the parents of all participants.

\section{RESULTS}

\section{Preparation: SAR Simulation}

The global SAR and peak local SAR of the virtual infant model in the centered position and $50 \mathrm{~mm}$ from the isocenter in feet direction $(-50-\mathrm{mm}$ $\mathrm{FH}$ ) did not exceed the SAR of the adult models. However, when infant Charlie was positioned $50 \mathrm{~mm}$ from isocenter in the head direction $(+50$ $\mathrm{mm} \mathrm{FH}$ ), global SAR levels and peak local SAR levels exceeded those of the adult models (by $+13 \%$ and $+12 \%$ compared with Duke, respectively) (Table 1).

The 10-g averaged local SAR in the head of the infant model was lower than that in the adult head for all positions. When the infant model was positioned +50-mm $\mathrm{FH}$, the local SAR was highest in the neck/shoulder transitions (Fig 3).

The SAR per $\mathrm{B}_{1}{ }^{2}$ was lower in the infant model than in the adult models, meaning that less power is needed to reach the same $B_{1}$, except for the +50 $\mathrm{mm} \mathrm{FH}$ position.

\section{Preparation: Acoustic Noise Protection}

The background noise in the sound booth was $28 \mathrm{~dB}(\mathrm{~A})$. The $7 \mathrm{~T}$ hood attenuated the acoustic noise by $8.5 \mathrm{~dB}$, and the $3 \mathrm{~T}$ hood, by $7 \mathrm{~dB}$ (Table 2).

Without hearing protection, the artificial ear measured $80 \mathrm{~dB}$ (A). The Alpine Muffy Baby reduced the acoustic noise level to $56 \mathrm{~dB}(\mathrm{~A})$, and the use of only the Natus Minimuffs resulted in $73.4 \mathrm{~dB}(\mathrm{~A})$. The combination of both, not totally closing the artificial ear, led to an acoustic noise level of $58 \mathrm{~dB}(\mathrm{~A})$. If they were both well-placed on the ear using the elastic head band, the level decreased to $47.8 \mathrm{~dB}(\mathrm{~A})$.

\section{Feasibility of MR Imaging}

Twelve infants have been included with a median gestational age of 28.2 weeks (range, 25.0-41.7 weeks), median birth weight of $1127 \mathrm{~g}$ (range, 585-4570 g), median postnatal age at MR imaging of 95 days (range, 31-114 days), and a median weight at MR 

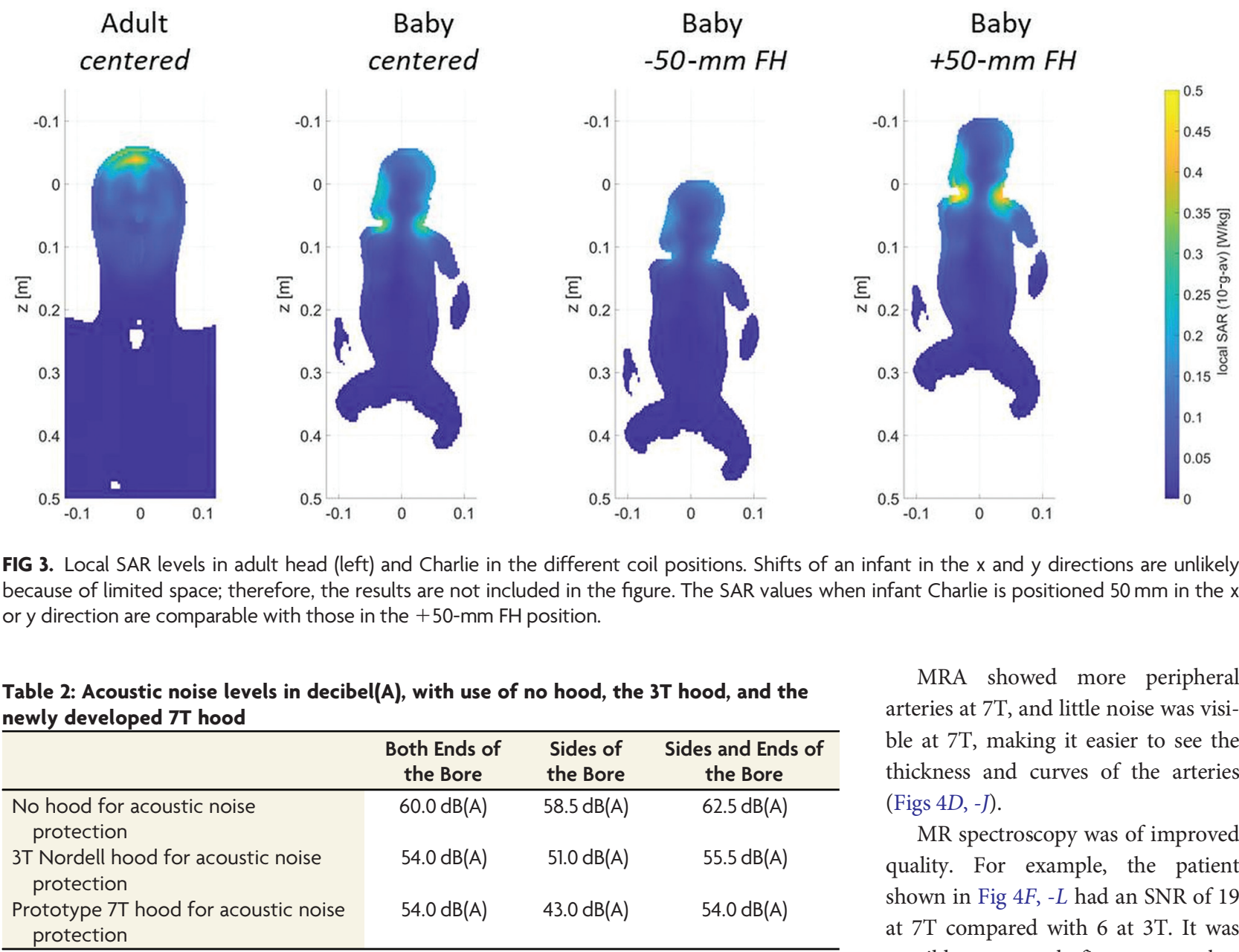

FIG 3. Local SAR levels in adult head (left) and Charlie in the different coil positions. Shifts of an infant in the $x$ and $y$ directions are unlikely because of limited space; therefore, the results are not included in the figure. The SAR values when infant Charlie is positioned $50 \mathrm{~mm}$ in the $\mathrm{x}$ or $y$ direction are comparable with those in the $+50-\mathrm{mm} \mathrm{FH}$ position.

Table 2: Acoustic noise levels in $\operatorname{decibel}(A)$, with use of no hood, the 3T hood, and the newly developed 7T hood

\begin{tabular}{lccc}
\hline & $\begin{array}{c}\text { Both Ends of } \\
\text { the Bore }\end{array}$ & $\begin{array}{c}\text { Sides of } \\
\text { the Bore }\end{array}$ & $\begin{array}{c}\text { Sides and Ends of } \\
\text { the Bore }\end{array}$ \\
\hline $\begin{array}{l}\text { No hood for acoustic noise } \\
\text { protection }\end{array}$ & $60.0 \mathrm{~dB}(\mathrm{~A})$ & $58.5 \mathrm{~dB}(\mathrm{~A})$ & $62.5 \mathrm{~dB}(\mathrm{~A})$ \\
$\begin{array}{l}\text { 3T Nordell hood for acoustic noise } \\
\text { protection }\end{array}$ & $54.0 \mathrm{~dB}(\mathrm{~A})$ & $51.0 \mathrm{~dB}(\mathrm{~A})$ & $55.5 \mathrm{~dB}(\mathrm{~A})$ \\
$\begin{array}{l}\text { Prototype 7T hood for acoustic noise } \\
\text { protection }\end{array}$ & $54.0 \mathrm{~dB}(\mathrm{~A})$ & $43.0 \mathrm{~dB}(\mathrm{~A})$ & $54.0 \mathrm{~dB}(\mathrm{~A})$ \\
\hline
\end{tabular}

imaging of $3322 \mathrm{~g}$ (range, 2715-6335 g). The clinical indications for the MR imaging scans were the following: MR imaging at term-equivalent age because of preterm birth before 28 weeks' gestation $(n=7)$; MR imaging at term-equivalent age because of white matter injury $(n=2)$; follow-up MR imaging at 3 months' corrected age because of a thalamic hemorrhage $(n=1)$ or hemorrhage in the temporal lobe $(n=1)$; and follow-up MR imaging at 6 weeks because of an arterial ischemic stroke $(n=1)$. Temperature, heart rate, peripheral oxygen saturation, and comfort scales were stable before, during, and after MR imaging. No serious adverse events related to the MR imaging occurred.

MRV at 7T provided good visibility of the different veins and sinuses: The superficial cerebral veins could be followed in detail (Fig 4A, $-G$ ).

Also, SWI at 7T was feasible and showed details of the deep venous circulation, i.e., the deep medullary veins (Fig 4B, $-H$ ).

Single-shot T2WI at 7T demonstrated good gray and white matter contrast. In 1 patient with a perinatal arterial stroke, perivascular spaces were seen at 7T that were not visible at 3T (Figs $4 C,-I)$. Otherwise, no clinically relevant additional findings were reported by the pediatric neuro radiologist (M.L.) at 7T. The gray and white matter differentiation at T1WI was suboptimal at 7T (Figs $4 E,-K)$.
MRA showed more peripheral arteries at 7T, and little noise was visible at $7 \mathrm{~T}$, making it easier to see the thickness and curves of the arteries (Figs $4 D,-J$ ).

MR spectroscopy was of improved quality. For example, the patient shown in Fig 4F, $-L$ had an SNR of 19 at $7 \mathrm{~T}$ compared with 6 at 3T. It was possible to correctly fit more metabolites with a Cramer-Rao Lower Bound of $<20 \%$ at $7 \mathrm{~T}$, such as $N$-acetyl aspartylglutamate, taurine, and glycine.

\section{DISCUSSION}

We demonstrated that scanning infants in a 7T scanner is feasible and results in good-quality images. While optimization of the sequences is ongoing, we already demonstrated that some sequences showed more details compared with 3T MR imaging.

Before scanning, simulated SAR levels at 7T were lower in the virtual infant than in adult models. ${ }^{18}$ When the infant's head was further in the coil than isocenter, or $5 \mathrm{~cm}$ in the $\mathrm{x}$ or $\mathrm{y}$ direction, SAR levels did exceed the adult situation. Thus, the center position of the infant in the coil is essential. Therefore, the position of the infant's head was constrained in the coil, making it mechanically impossible to put the infant's head farther in the coil than center position. Differences in the SAR due to intersubject variability cannot be completely ruled out. However, previous simulations at $3 \mathrm{~T}$ showed that different-sized infant models and different positions did not result in major differences in simulated SAR levels. ${ }^{21}$

The SAR simulations had 2 important limitations. The first limitation is that the Sim4Life model of Charlie uses the dielectric values of adults, which might slightly differ from infant dielectric properties. The dielectric values of human infants are unknown 


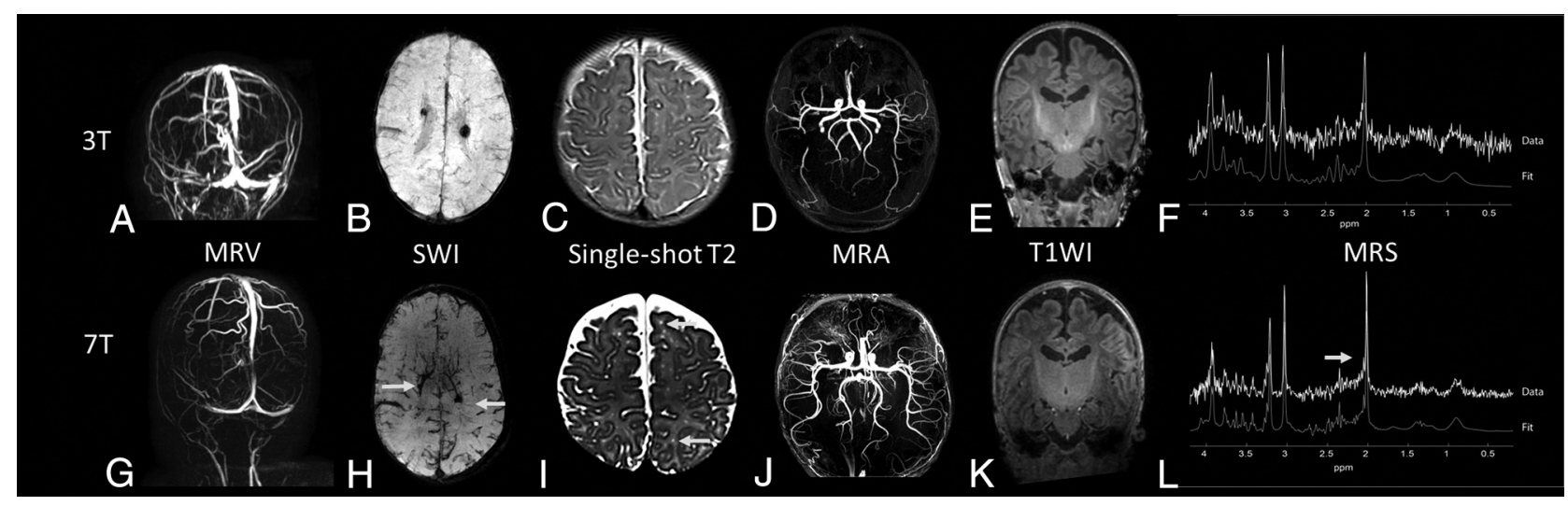

FIG 4. Examples of images of different patients at $3 T$ (upper row) versus $7 T$ MR imaging (lower row). $A$ and $G, M R V$ at $3 T$ and $7 T$, respectively, of a preterm infant at term-equivalent age. $B$ and $H$, An SWI at, respectively, 3T and 7T of a preterm infant at term-equivalent age. $C$ and $I$, The 6-week follow-up single-shot T2-weighted image of a term-born infant with a perinatal stroke. The arrows indicate perivascular spaces that were better visualized at 3T compared with 7T. D and J, A 3-month follow-up MRA at 3T and 7T of a term-born infant with an occipital stroke. $E$ and $K$, TTWI (MPRAGE) of a preterm-born infant at term-equivalent age. $F$ and $L$, An MR spectroscopy spectrum at $3 T$ and $7 T$ of a preterm infant at term-equivalent age, both with a comparable ROI in the left basal ganglia/thalami region.

and require further research. In the study of Malik et al, ${ }^{21}$ conversion of adult dielectric values was based on rat data; however, these are not validated. Second, only 1 virtual model of a 2 -month-old infant was available, which cannot be completely translated to an infant of term-equivalent age. Head circumference and body composition differed between term-equivalent age and 2 months of age. Malik et al showed that term neonates with smaller head sizes or lower body weight had lower SAR depositions, suggesting that the 2-month-old infant model does not underestimate SAR values. Regarding body composition, Malik et al simulated the effect of fat percentage on SAR depositions in neonates in 2 extreme scenarios: 1 model with only skin and 1 model with a thick layer of pure fat. The model with only skin had $10 \%$ higher peak local SAR depositions. ${ }^{21}$ The fat percentage of neonates is lower compared with 2 month-old infants. ${ }^{22,23}$ In the worst case scenario, a neonate might have a higher peak local SAR up to $10 \%$ compared with a 2 month-old infant based on fat composition. This will still not exceed the safety limits of the FDA because the 7T MR scanner, Best, the Netherlands has implemented an additional safety factor larger than 2. Furthermore, the global SAR levels of Charlie in the centered position were $6 \%$ lower compared with the adult model, and the peak local SAR was $26 \%$ lower, leading to an additional safety margin. Adult limits are, therefore, still safe to use.

Another concern might be that the thermoregulation in neonates is immature compared with adults, so the effect of SAR values on body temperature might differ between neonates and adults. $^{21}$ Neonates have less isolating subcutaneous fat and a larger surface-to-body weight ratio, making them more prone to develop hypothermia. ${ }^{21,24-26}$ The risk of high local peak SAR values in neonates is lower compared with adults because less power is needed in neonates to reach the same $B_{1}+$. Furthermore, the risk of high local peak SAR is reduced by the above-described safety margins (Table 1).

No MR imaging-related adverse events occurred in the infants scanned at 7T in this pilot study, and comfort scales were stable, which are both indicators that infants did tolerate the higher main static field.
The possible improvements in the quality of SWI and singleshot T2WI are caused by a shorter T2-relaxation time, improved spatial resolution, and increased susceptibility. ${ }^{5}$ These might enable physicians to assess the extent of injury on a microstructural level: diagnosing microbleeds and polymicrogyria and thereby improving the prediction of neurodevelopmental outcome. ${ }^{27-29}$

As expected, the quality of T1WI at 7T was worse compared with $3 \mathrm{~T}$ in infants. The T1-relaxation time increases at higher field strengths. ${ }^{13}$ Furthermore, the brains of neonates have a relatively high water content, which results in less contrast between white and gray matter. To compensate for this longer T1 relaxation time, the TR can be increased, but this increase leads to longer scanning time, which is also not preferable in neonates. ${ }^{6,13}$ On the other hand, this increased T1-relaxation time enables higher quality angiography, which, in the future, can help, for example, to evaluate small perforator strokes. ${ }^{6,10}$

For MR spectroscopy, the increased chemical shift dispersion at $7 \mathrm{~T}$ results in less overlap between the different metabolite peaks; also, the SNR is increased ( $>2$-fold). Of note is that the maximal required $B_{1}$ for $M R$ spectroscopy cannot be achieved when the infant is in the $-50-\mathrm{mm}$ position in the coil. This can happen if the shoulders do not fit in the head coil when the infant is wrapped in the vacuum matress. In such cases, MR spectroscopy at 7T has SNR comparable with that of 3T, but with the advantage of less overlap between metabolite peaks. Nevertheless, 7T MR spectroscopy enabled more accurate detection of $\mathrm{N}$-acetyl aspartylglutamate, taurine, and glycine and possibly other metabolites such as glutamate, gammaaminobutyric acid, and myo-inositol, as has been described in adults. ${ }^{5,6}$ This feature could be helpful for the diagnosis of metabolic diseases and neuronal injury but can also provide information about the biochemical development of the neonatal brain.

In the future, 7T might be particularly helpful to answer specific questions about the diagnosis or outcome in, for example, infants with small (perforator) strokes, metabolic diseases, or unexplained neurologic symptoms, i.e., seizures. The clinical 
implications and the additional value of $7 \mathrm{~T}$ in infants should be investigated in larger 7T MR imaging studies. We did not scan preterm neonates; the safety and feasibility of 7T MR imaging in these neonates should also be investigated in the future.

\section{CONCLUSIONS}

This pilot study shows, for the first time, that 7T ultra-high-field MR imaging is feasible in infants. Good-quality images could be obtained, with some sequences providing additional details compared with 3T. Positioning of the infant in the isocenter of the coil is important for SAR safety.

\section{ACKNOWLEDGMENTS}

We thank Patrick Stroosnijder for helping with the audiology tests and the physician assistants of the neonatal intensive care unit for their help and supervision during the MR imaging scans.

Disclosures: Kim V. Annink—RELATED: Grant: Horizon 2020 grant, grant Dr. C.J. Vaillant Foundation, Comments: The study was funded by the Dr. C.J. Vaillant Foundation. The PhD position of the first author Kim Annink is supported by Horizon 2020 Research and Innovation Programme of the European Union (grant agreement No 667224, ALBINO).* Niek E. van der Aa—RELATED: Grant: Dr. C.J. Vaillant Foundation.* Floris Groenendaal—UNRELATED: Expert Testimony: Court, Comments: expert witness in medicolegal cases of perinatal asphyxia; Grants/ Grants Pending: Neurophyxia, Comments: unrestricted grant from Neurophyxia for research on neuroprotection*; Royalties: UpToDate, Comments: royalties for publication.* Erik R. Huijing - UNRELATED: Employment: University Medical Center Utrecht. Fredy Visser-RELATED: Grant: Dr. C.J. Vaillant Foundation.* Alexander J. E. Raaijmakers - UNRELATED: Employment: University Medical Center Utrecht. RELATED: Grant: Dr. C.J. Vaillant Foundation.* Evita C. Wiegers-RELATED: Grant: Dr. C.J. Vaillant Foundation.* Dennis W.J. Klomp—RELATED: Grant: Dr. C.J. Vaillant Foundation.* Jannie P. Wijnen—RELATED: Grant. Dr. C.J. Vaillant Foundation.* Manon J.N.L. Benders - RELATED: Grant: Dr. C.J. Vaillant Foundation.* *Money paid to the institution.

\section{REFERENCES}

1. Semple B, Blomgren K, Gimlin K, et al. Brain development in rodents and humans: identifying benchmarks of maturation and vulnerability to injury across species. Prog Neurobiol 2013;106107:1-16 CrossRef Medline

2. Arthur R. Magnetic resonance imaging in preterm infants. Pediatr Radiol 2006;36:593-607 CrossRef Medline

3. de Vries L, Benders M, Groenendaal F. Imaging the premature brain: ultrasound or MRI? Neuroradiology 2013;55:13-22 CrossRef Medline

4. Rutherford M, Malamateniou C, Zeka J, et al. MR imaging of the neonatal brain at 3 Tesla. Eur J Paediatr Neurol 2004;8:281-89 CrossRef Medline

5. Kolk AG, Van Der Hendrikse J, Zwanenburg JJM, et al. Clinical applications of 7 T MRI in the brain. Eur J Radiol 2013;82:708-18 CrossRef Medline

6. Ditchfield M. 3 T MRI in paediatrics: challenges and clinical applications. Eur J Radiol 2008;68:309-19 CrossRef Medline

7. Robitaille PL, Abduljalil AM, Kangarlu A, et al. Human magnetic resonance imaging at 8T. NMR Biomed 1998;11:263-65 CrossRef Medline

8. Springer E, Dymerska B, Cardoso PL, et al. Comparison of routine brain imaging at $3 \mathrm{~T}$ and $7 \mathrm{~T}$. Invest Radiol 2017;51:469-82 CrossRef Medline
9. De Cocker LJ. Cerebellovascular disease: magnetic resonance imaging. J Belgian Soc Radiol 2016;100:1-6 CrossRef Medline

10. Park C, Kang C, Kim Y, et al. Advances in MR angiography with 7T MRI: from microvascular imaging to functional angiography. Neuroimage 2018;168:269-78 CrossRef Medline

11. Stefanits H, Springer E, Pataraia E, et al. Seven-Tesla MRI of hippocampal sclerosis an in vivo feasibility study with histological correlations. Invest Radiol 2017;52:666-71 CrossRef Medline

12. Shellock FG, Crues JV. Radiology MR procedures: biologic effects, safety, and patient care. Radiology 2004;232:635-52 CrossRef Medline

13. Tocchio S, Kline-Fath B, Kanal E, et al. MRI evaluation and safety in the developing brain. Semin Perinatol 2015;39:73-104 CrossRef Medline

14. Theysohn JM, Maderwald S, Kraff O, et al. Subjective acceptance of 7 Tesla MRI for human imaging. MAGMA 2008;21:63-72 CrossRef Medline

15. Kraff O, Quick HH. 7T: physics, safety, and potential clinical applications. J Magn Reson Imaging 2017;46:1573-89 CrossRef Medline

16. Harris AD, Singer HS, Horska A, et al. GABA and glutamate in children with primary complex motor stereotypies: a1H MRS study at 7T. AJNR Am J Neuroradiol 2016;37:552-57 CrossRef Medline

17. U.S. Department of Health and Human Services; Food and Drug Administration; Center for Devices and Radiological Health. Criteria for Significant Risk Investigations of Magnetic Resonance Diagnostic Devices 2014. http://www.fda.gov/downloads/RegulatoryInformation/ Guidances/ucm126418.pdf. Accessed September 6, 2019

18. Christ A, Kainz W, Hahn EG, et al. The Virtual Family: development of surface-based anatomical models of two adults and two children for dosimetric simulations. Phys Med Biol 2010;55:N23-38 CrossRef Medline

19. Nordell A, Lundh M, Horsch S, et al. The acoustic hood: a patientindependent device improving acoustic noise protection during neonatal magnetic resonance imaging. Acta Paediatr 2009;98:127883 CrossRef Medline

20. Ambuel B, Hamlett KW, Marx CM, et al. Assessing distress in pediatric intensive care environments: the COMFORT scale. J Pediatr Psychol 1992;17:95-109 CrossRef Medline

21. Malik SJ, Beqiri A, Price AN, et al. Specific absorption rate in neonates undergoing magnetic resonance procedures at $1.5 \mathrm{~T}$ and $3 \mathrm{~T}$. NMR Biomed 2015;28:344-52 CrossRef Medline

22. Demerath EW, Fields DA. Body composition assessment in the infant. Am J Hum Biol 2014;26:291-304 CrossRef Medline

23. Fields DA, Gilchrist JM, Catalano PM, et al. Longitudinal body composition data in exclusively breast-fed infants: a multicenter study. Obesity (Silver Spring). 2011;19:1887-91 CrossRef Medline

24. Sharma A, Ford S, Calvert J. Adaptation for life: a review of neonatal physiology. Anaesthesia \& Intensive Care Med 2011;12:85-90 CrossRef

25. Plaisier A, Raets MMA, van der Starre C, et al. Safety of routine early MRI in preterm infants. Pediatr Radiol 2012;42:1205-11 CrossRef Medline

26. Don Paul JM, Perkins EJ, Pereira-Fantini PM, et al. Surgery and magnetic resonance imaging increase the risk of hypothermia in infants. J Paediatr Child Health 2018;54:426-31 CrossRef Medline

27. Brundel M, Heringa SM, de Bresser J, et al. High prevalence of cerebral microbleeds at 7 Tesla MRI in patients with early Alzheimer's disease. J Alzheimers Dis 2012;31:259-63 CrossRef Medline

28. De Ciantis A, Barkovich AJ, Cosottini M, et al. Ultra-high-field MR imaging in polymicrogyria and epilepsy. AJNR Am J Neuroradiol 2015;36:309-16 CrossRef Medline

29. Cosottini M, Donatelli G, Costagli M, et al. High-resolution 7T MR imaging of the motor cortex in amyotrophic lateral sclerosis. AJNR Am J Neuroradiol 2016;37:455-61 CrossRef Medline 
$\mathrm{n}$ the article "Introduction of Ultra-High-Field MR Imaging in Infants: Preparations and Feasibility" (K.V. Annink, N.E. van der Aa,

J. Dudink, et al. AJNR Am J Neuroradiol 2020;41:1532-37 10.3174/ajnr.A6702) Table 1 and Fig 3 contained errors. The correct table and figure are the following:

Duke Centered Ella Centered Charlie Centered Charlie $-50 \mathrm{~mm}$ FH Charlie $+50 \mathrm{~mm}$ FH

\begin{tabular}{l}
\hline Global SAR \\
Average SAR for $1 \mathrm{~W}$ input power $(\mathrm{W} / \mathrm{kg})$ \\
Average SAR per $\mathrm{B}^{2}(\mathrm{~W} / \mathrm{kg} / \mu \mathrm{T} 2)$ \\
Average $\mathrm{B}_{1}^{+}$in central section for $1 \mathrm{~W}$ \\
input power $(\mu \mathrm{T})^{\mathrm{a}}$ \\
Peak SAR \\
Peak local SAR $(10 \mathrm{~g}$ averaged) for $1 \mathrm{~W}$ \\
input power $(\mathrm{W} / \mathrm{kg})$ \\
Peak local SAR $\left(10 \mathrm{~g}\right.$ averaged) per $\mathrm{B}_{1}{ }^{2}$ \\
$(\mathrm{W} / \mathrm{kg} / \mu \mathrm{T} 2)$
\end{tabular}

\begin{tabular}{lllll}
0.066 & 0.069 & 0.091 & 0.075 & 0.109 \\
0.462 & 0.465 & 0.320 & 0.477 & 0.484 \\
0.379 & 0.385 & 0.542 & 0.397 & 0.475 \\
& & & & \\
0.435 & 0.398 & 0.487 & 0.345 & 0.643 \\
3.04 & 2.63 & 1.72 & 2.19 & 2.85 \\
\hline
\end{tabular}

${ }^{a}$ The power optimization procedure of the MR imaging scanner software calibrates the needed input power to achieve a certain $B_{1}$ in the subject. This calibration is based on the average $\mathrm{B}_{1}{ }^{+}$in a central section of the subject (brain in this case).
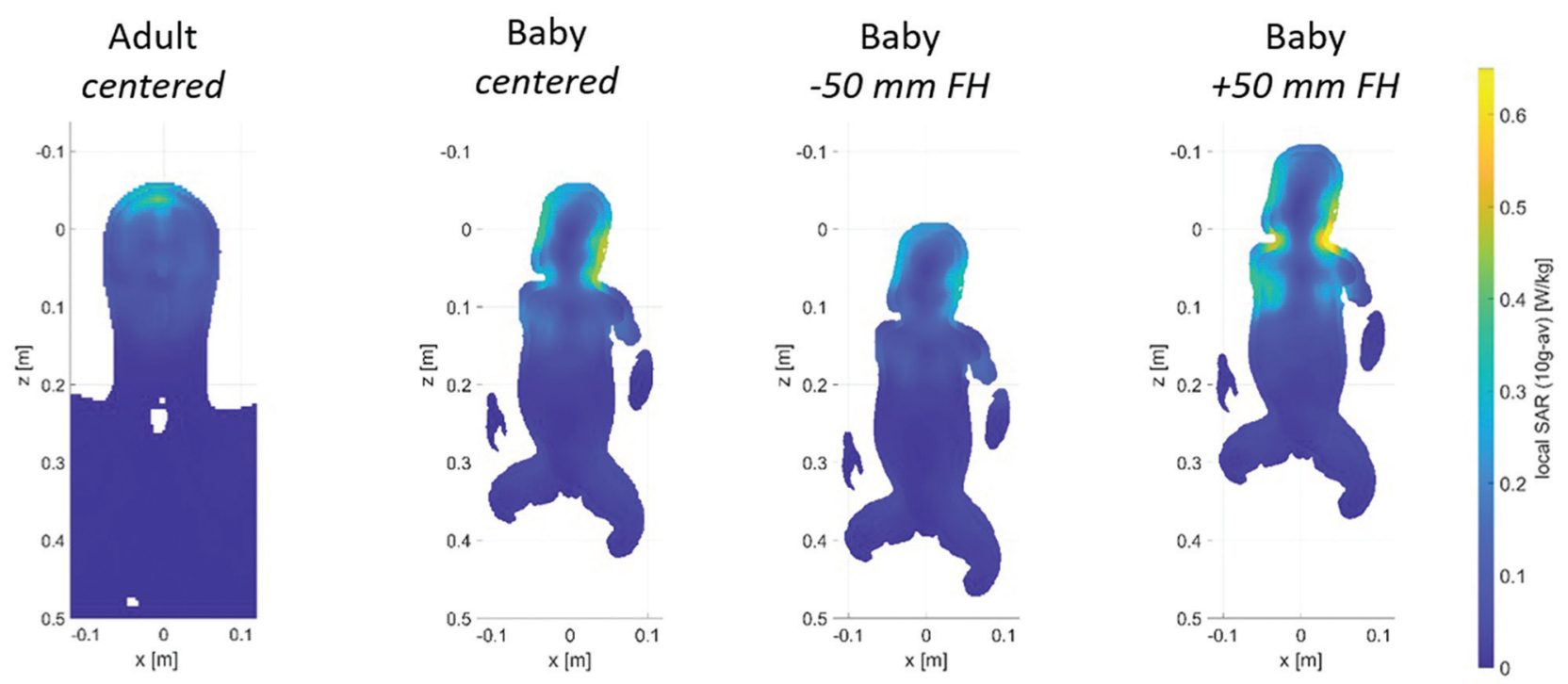

FIG 3. Local SAR levels in adult head (left) and Charlie in the different coil positions. Shifts of an infant in the $x$ and $y$ directions are unlikely because of limited space; therefore, the results are not included in the figure. The SAR values when infant Charlie is positioned $50 \mathrm{~mm}$ in the $\mathrm{x}$ or $\mathrm{y}$ direction are comparable with those in the $+50-\mathrm{mm} \mathrm{FH}$ position.

\section{$\underline{\text { Textual Changes }}$}

\section{ABSTRACT}

BACKGROUND AND PURPOSE: Cerebral MR imaging in infants is usually performed with a field strength of up to $3 \mathrm{~T}$. In adults, a growing number of studies have shown added diagnostic value of 7T MR imaging. 7T MR imaging might be of additional value in infants with unexplained seizures, for example. The aim of this study was to investigate the feasibility of 7T MR imaging in infants. We provide information about the safety preparations and show the first MR images of infants at 7T.

MATERIALS AND METHODS: Specific absorption rate levels during 7T were simulated in Sim4life by using infant and adult models. A newly developed acoustic hood was used to guarantee hearing protection. Acoustic noise damping of this hood was measured and compared with the 3T Nordell hood and no hood. In this prospective pilot study, clinically stable infants, between term-equivalent age 
and the corrected age of 3 months, underwent 7T MR imaging immediately after their standard 3T MR imaging. The 7T scan protocols were developed and optimized while scanning this cohort.

RESULTS: Global and peak specific absorption rate levels in the infant model in the centered position and 50-mm feet direction did not exceed the values used by the scanner to calculate energy deposition. Hearing protection was guaranteed with the new hood. Twelve infants were scanned. No MR imaging-related adverse events occurred. It was feasible to obtain good-quality imaging at 7T for MRA, MRV, SWI, single-shot T2WI, and MR spectroscopy. T1WI had lower quality at 7T.

CONCLUSIONS: 7T MR imaging is feasible in infants, and good-quality scans could be obtained.

\section{RESULTS}

\section{Preparation: SAR Simulation}

The global SAR and peak local SAR of the virtual infant model did exceed the SAR of the adult models (in the center position by $+38 \%$ and $+12 \%$ compared with Duke, respectively) (Table 1 ). However, the calculated SAR per B1 ${ }^{2}$ values are all below the values used by the scanner to calculate energy deposition $\left(1.83 \mathrm{~W} / \mathrm{kg} / \mathrm{uT}^{2}\right.$ for global SAR and $4.96 \mathrm{~W} / \mathrm{kg} / \mathrm{uT}^{2}$ for peak local SAR. Numbers as provided by the manufacturer).

Global and peak local SAR levels were highest when the infant model was positioned +50 -mm FH. Furthermore, in this position, the local SAR showed hotspots in the neck/shoulder transitions (Fig 3).

The SAR per $\mathrm{B}^{2}$ was lower in the infant model in the center position than in the adult models, meaning that less power is needed to reach the same $\mathrm{B} 1$.

\section{DISCUSSION}

We demonstrated that scanning infants in a 7T scanner is feasible and results in good-quality images. While optimization of the sequences is ongoing, we already demonstrated that some sequences showed more details compared with 3T MR imaging.

When the infant's head was further in the coil than isocenter, SAR levels were highest. Thus, the center position of the infant in the coil is essential. Therefore, the position of the infant's head was constrained in the coil, making it mechanically impossible to put the infant's head farther in the coil than center position. 